\title{
Glycogen Synthase Kinase-3 Regulates Production of Amyloid- $\beta$ Peptides and Tau Phosphorylation in Diabetic Rat Brain
}

\author{
Zhong-Sen Qu, ${ }^{1}$ Liang Li, ${ }^{2}$ Xiao-Jiang Sun, ${ }^{1}$ Yu-Wu Zhao, ${ }^{1}$ Jin Zhang, ${ }^{1}$ Zhi Geng, \\ Jian-Liang Fu, ${ }^{1}$ and Qing-Guo Ren $^{3}$ \\ ${ }^{1}$ Department of Neurology, The Sixth People's Hospital Affiliated Shanghai Jiao Tong University, Yi Shan Road 600, \\ Shanghai 200233, China \\ ${ }^{2}$ Department of Neurology, The Central Hospital Affiliated Qingdao University, Qingdao 266042, China \\ ${ }^{3}$ Department of Pathophysiology, Key Laboratory of Neurological Diseases of Hubei Province, Tongji Medical College, \\ Huazhong University of Science and Technology, Wuhan 430030, China
}

Correspondence should be addressed to Zhong-Sen Qu; qvzhsen@126.com

Received 23 December 2013; Accepted 25 January 2014; Published 3 April 2014

Academic Editors: T. Arendt, T. Pannicke, and Ü. Tan

Copyright () 2014 Zhong-Sen Qu et al. This is an open access article distributed under the Creative Commons Attribution License, which permits unrestricted use, distribution, and reproduction in any medium, provided the original work is properly cited.

The pathogenesis of diabetic neurological complications is not fully understood. Diabetes mellitus (DM) and Alzheimer's disease (AD) are characterized by amyloid deposits. Glycogen synthase kinase-3 (GSK-3) plays an important role in the pathogenesis of AD and DM. Here we tried to investigate the production of amyloid- $\beta$ peptides $(\mathrm{A} \beta)$ and phosphorylation of microtubule-associated protein tau in DM rats and elucidate the role of GSK-3 and Akt (protein kinase B, PKB) in these processes. Streptozotocin injectioninduced DM rats displayed an increased GSK-3 activity, decreased activity and expression of Akt. And A $\beta 40$ and A $\beta 42$ were found overproduced and the microtubule-associated protein tau was hyperphosphorylated in the hippocampus. Furthermore, selective inhibition of GSK- 3 by lithium could attenuate the conditions of $A \beta$ overproduction and tau hyperphosphorylation. Taken together, our studies suggest that GSK-3 regulates both the production of $\mathrm{A} \beta$ and the phosphorylation of tau in rat brain and may therefore contribute to DM caused AD-like neurological defects.

\section{Introduction}

Alzheimer's disease (AD) is characterized by the presence of two pathological protein deposits: extracellular senile plaques (SP) and intracellular neurofibrillary tangles (NFTs). The former is composed of $\beta$-amyloid (A $\beta)$ [1] and the latter is formed by bundles of paired helical filaments (PHFs), which are mainly constituted by abnormal hyperphosphorylated tau protein [2]. Several protein kinases may take part in these pathological processes, including cyclin-dependent kinase 5 (cdk-5), GSK-3, and protein kinase A (PKA). Activated GSK3 increases the production of $\mathrm{A} \beta$ peptides by promoting of $\gamma$-secretase activity and induces the aggregation and deposition of $A \beta$ [3]. On the other hand, GSK-3 regulates tau hyperphosphorylation at ser198/ser199/ser202 sites and ser396/ser404 sites [4]. Furthermore, as a downregulator of insulin signaling, GSK-3 is regulated by Akt [5].
The available epidemiological data are largely inconclusive with regard to the contribution of diabetes mellitus to cognitive impairment and AD-type neurodegeneration $[6,7]$. Both diabetes and $\mathrm{AD}$ are characterized by localized amyloid deposits that progress during the course of the diseases [8]. In hippocampal neurons of diabetic mice, the stains of $A \beta 40$ and $A \beta 42$ are increased, but the expression of GSK-3 is weakened by immunohistochemistry [9]. In AD-like Tg2576 mice, diet-induced insulin resistance promotes $A \beta 40$ and $A \beta 42$ generation in the brain. Further study suggest that PI3kinase/PS473-Akt/PKB is reduced in these brains and suggest that GSK-3 as a downsteam kinase of these kinases may affect the production of $A \beta[10]$. In the skeletal muscle of type II diabetes mellitus patients, GSK-3 activity and its expression level are significantly higher [11]. Increased GSK-3 activity is also found in the development of insulin resistance and 
type II diabetes fat tissue of C57BL/6J mice [12]. Immunohistochemical results show that ser198/ser199/ser202 sites are hyperphosphorylated in the hippocampus of diabetic mice, but the expression of GSK-3 is reduced [13]. In the brain of insulin knockout mice, hyperphosphorylation of tau at threonine 231 and of the neurofilament is exhibited, but GSK$3 \beta$ activity was inhibited [14].

All of the above evidences imply that GSK-3 may be linked to both $\mathrm{A} \beta$ production and tau hyperphosphorylation during the course of diabetes. To better understand the mechanisms of AD-like changes in diabetic rat brain, we investigated the activity of GSK-3 and Akt and the expression of Akt; then $\mathrm{A} \beta$ production and tau phosphorylation was determined. Furthermore, the role of GSK-3 was explored by using $\mathrm{LiCl}$ as a specific inhibitor [15].

\section{Materials and Methods}

2.1. Antibodies and Chemicals. The primary $\mathrm{A} \beta$ antibodies G2-10 (capture antibody for A $\beta_{40}$ ), G2-11 (capture antibody for $\mathrm{A} \beta_{42}$ ), and $\mathrm{WO}_{2}$ (detection antibody) used for ELISA were purchased from A $\beta$ eta Company (Germany), and standard synthetic $A \beta$ peptides were obtained from Sigma (St. Louis, MO, USA). Antibodies against phospho-Ser ${ }^{473}$ Akt and total Akt were purchased from Cell Signaling technology (Beverly, MA, USA). Monoclonal antibodies PHF-1, which labels tau phosphorylated at Ser-396 and/or Ser-404, and Tau-1, which labels tau where neither serines 198, 199, or 202 are phosphorylated, were gifts from Dr. Peter Davies (Albert Einstein College of Medicine, Bronx, NY, USA) and Dr. Lester Binder (Northwestern University, Chicago, IL, USA), respectively. Polyclonal antibody 11le, which reacts with the total tau, was a kind gift from Drs. Iqbal K and Grundke-Iqbal I (New York State Institute for Basic Research, Staten Island, NY, USA). Phospho-GS peptide, a specific GSK-3 substrate, was obtained from Upstate Biotechnology Inc. (Lake Placid, NY, USA). Bicinchoninic acid (BCA) protein detection kit and TMB were obtained from Pierce (Rockford, IL, USA). $\left[\gamma^{-32} \mathrm{P}\right]$ ATP was obtained from Beijing Yahui Biologic and Medicinal Engineering Co. (Beijing, China). Goat antirabbit or goat anti-mouse peroxidase-conjugated secondary antibodies and phosphocellulose paper were obtained from Pierce Chemical Co. (Rockford, IL, USA). Polyclonal and monoclonal Histostain-SP kits were obtained from Zymed Laboratories Inc. (South San Francisco, CA, USA). Streptozotocin (STZ), diaminobenzidine, $\mathrm{LiCl}$ (a specific inhibitor of GSK-3), and other chemicals were purchased from Sigma (St. Louis, MO, USA).

2.2. Establishment of DM Rat Model. Four-month-old Sprague-Dawley rats (Grade II, male, weight 200-250 g, supplied by Experimental Animal Center of Tongji Medical College) were divided into 4 groups: control group, diabetes mellitus (DM) group, $\mathrm{DM}$ plus $\mathrm{NaCl}$ group, and $\mathrm{DM}$ plus $\mathrm{LiCl}$ group by random. Except for control rats, the other rats received intraperitoneal injection with $55 \mathrm{mg} / \mathrm{kg}$ streptozotocin (STZ). The DM rats were determined by fasting blood glucose $\geq 16.7 \mathrm{mmol} / 72 \mathrm{~h}$ after streptozotocin injection. DM plus $\mathrm{NaCl}$ group: $24 \mathrm{~h}$ following STZ injection, the rats were administered by intraperitoneal injection $0.4 \mathrm{~mL}$ of $0.3 \mathrm{M} \mathrm{NaCl}$ for 10 days. $\mathrm{DM}$ plus $\mathrm{LiCl}$ group: $24 \mathrm{~h}$ following STZ injection, the rats were injected intraperitoneally with $400 \mu \mathrm{L}$ of $0.3 \mathrm{M} \mathrm{LiCl}$ for 10 days.

\subsection{Preparation of Rat Hippocampal Extracts. Following} continuous injection of $\mathrm{NaCl}$ or $\mathrm{LiCl}$ for 10 days, the rats were killed. The hippocampus was immediately removed and homogenized at $4^{\circ} \mathrm{C}$ using a Teflon glass homogenizer in $50 \mathrm{mmol}$ Tris- $\mathrm{HCl}, \mathrm{pH} 7.4,150 \mathrm{mmol} \mathrm{NaCl}, 10 \mathrm{mmol}$ $\mathrm{NaF}, 1 \mathrm{mmol} \mathrm{Na} \mathrm{VO}_{4}, 10 \mathrm{mmol} \beta$-mercaptoethanol, $5 \mathrm{mmol}$ EDTA, 2 mmol benzamidine, $1.0 \mathrm{mmol}$ phenylmethylsulfonyl fluoride, $5 \mu \mathrm{g} / \mathrm{mL}$ leupeptin, $5 \mu \mathrm{g} / \mathrm{mL}$ aprotinin, and $2 \mu \mathrm{g} / \mathrm{mL}$ pepstatin. The tissue homogenates were then divided into two portions. One portion of each homogenate was centrifuged at $12,000 \times \mathrm{g}$ for $20 \mathrm{~min}$ at $4^{\circ} \mathrm{C}$, and the resulting supernatant was stored at $-80^{\circ} \mathrm{C}$ for assaying activities of protein kinases. The other portion was mixed in $2: 1(\mathrm{v} / \mathrm{v})$ ratio with lysis buffer containing $200 \mathrm{mmol}$ Tris- $\mathrm{HCl}, \mathrm{pH}$ 7.6, 8\% SDS, $40 \%$ glycerol, boiled for $10 \mathrm{~min}$ in a water bath, and then centrifuged at $12,000 \times \mathrm{g}$ for $30 \mathrm{~min}$, and the supernatant was stored at $-80^{\circ} \mathrm{C}$ for Western blot analysis. The concentration of protein in the hippocampal extracts was measured by BCA kit according to the manufacturer's instructions (Pierce, Cheshire, UK).

2.4. Assay of GSK-3 and Akt Activity. The GSK-3 activity in rat hippocampal exacts was measured using phosphoGS peptide 2 (Upstate, Lake Placid, NY, USA) as described previously [16]. Briefly, tissue extracts, $7.5 \mu \mathrm{g}$ proteins were incubated for $30 \mathrm{~min}$ at $30^{\circ} \mathrm{C}$ with $20 \mu \mathrm{M}$ peptide substrate and $200 \mu \mathrm{mol}\left[\gamma^{-32} \mathrm{P}\right]$ ATP $(1,500 \mathrm{cpm} / \mathrm{pmol}$ ATP $)$ in $30 \mathrm{mmol}$ Tris, pH 7.4, $10 \mathrm{mmol} \mathrm{MgCl}_{2}, 10 \mathrm{mmol} \mathrm{NaF}, 1 \mathrm{mmol}$ $\mathrm{Na}_{3} \mathrm{VO}_{4}, 2 \mathrm{mmol}$ EGTA, and $10 \mathrm{mmol} \beta$-mercaptoethanol in a total volume of $25 \mu \mathrm{L}$. The reaction was stopped by addition of $25 \mu \mathrm{L}$ of $300 \mathrm{mMO}$-phosphoric acid. The reaction mixture was applied in triplicates on phosphocellulose paper (pierce). The filters were washed three times with $75 \mathrm{mmol}$ $O$-phosphoric acid, dried, and counted by liquid scintillation counter. GSK-3 activities was calculated with picomoles of phosphate incorporated $/ \mathrm{mg}$ protein $/ \mathrm{min}$ at $30^{\circ} \mathrm{C}$ and expressed as relative activity against control. The Akt activity was measured using histone $2 \mathrm{~B}$ as a substrate as described previously $[17,18]$. Briefly, after the immunoprecipitates were washed with lysis buffer and kinase buffer, $40 \mu \mathrm{L}$ kinase buffer containing $200 \mu \mathrm{M}[\gamma$-32P] $(5 \mu \mathrm{Ci}), 100 \mu \mathrm{M}$ ATP, $1 \mu \mathrm{g} / \mu \mathrm{L}$ histone $2 \mathrm{~B}$; then the samples were incubated at $30^{\circ} \mathrm{C}$ for $15 \mathrm{~min}$ and spotted onto P81 filter papers; the filter papers were washed by $75 \mathrm{mM} O$-phosphoric acid, dried, and counted by liquid scintillation counter. Akt activity was also expressed as relative activity against control.

2.5. Measurement of $A \beta$ in Hippocampus of the Rats. The $\mathrm{A} \beta 40$ and $\mathrm{A} \beta 42$ in the hippocampus were measured by a Sandwich enzyme-linked immunosorbent assay (ELISA) using antibodies as described previously [19]. Experiments were performed in a 96-well plate. Briefly, affinity-purified 


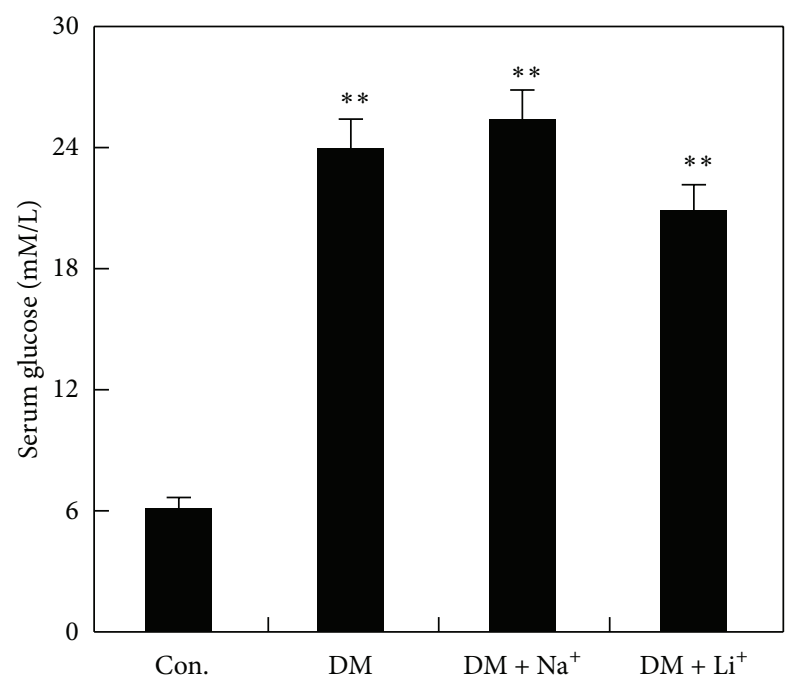

Figure 1: The level of serum glucose of the rats. $72 \mathrm{~h}$ following streptozotocin injection, the levels of serum glucose in DM group, $\mathrm{DM}$ plus $\mathrm{NaCl}$ group, and $\mathrm{DM}$ plus $\mathrm{LiCl}$ group increased obviously. ${ }^{* *} P<0.01$ versus control group.

mAb G2-10 (0.5 $\mu \mathrm{g} /$ well) was applied as the capture antibody for $\mathrm{A} \beta_{40}, \mathrm{mAb} \mathrm{G} 2-11(1 \mu \mathrm{g} /$ well $)$ was used as a capture antibody for $\mathrm{A} \beta_{42}$, and $\mathrm{mAb} \mathrm{WO}_{2}$ was used as a detection antibody. Neutravidin-horseradish peroxidase and TMB were used for reporter system and absorbance values at $450 \mathrm{~nm}$ were determined with microplate reader (TECAN, Austria). Levels of $\mathrm{A} \beta$ were expressed as a relative level against control. Each sample was tested in triplicate in each experiment.

2.6. Evaluation of Tau Phosphorylation and Expression of Akt. The phosphorylation of tau at various sites was determined by Western blot as described formerly [20]. For immunoblotting, about $20 \mu \mathrm{g}$ of proteins were loaded in each lane. Proteins were separated by SDS-PAGE and transferred to polyvinylidene difluoride membranes (Amersham Pharmacia Biotech, NJ, USA). After being blocked for $1 \mathrm{~h}$ in a solution of 5\% nonfat dry milk in TBS/Tween 20, membranes were immunoblotted using primary antibodies PHF-1 (1:500), Tau-1 $(1: 30,000)$, and 11le $(1: 3,000)$ at $4^{\circ} \mathrm{C}$ overnight and developed with alkaline phosphatase-labeled $\operatorname{IgG}(0.5 \mathrm{~g} / \mathrm{mL}$, Amersham Pharmacia, NJ, USA) as secondary antibodies. 5bromo-4-chloro-3-indolyl-phosphate/nitro blue tetrazolium (BCIP/NBT) was used as substrate [2]. Detection of the phosphorylation of Akt was performed with antibodies to phospho-Ser ${ }^{473}$ Akt and total Akt (Cell Signaling technology) (dilution 1:800); immunoblots were developed using horse radish peroxidase-conjugated goat anti-rabbit IgG $(1: 2000)$ followed by detection with enhanced chemiluminescence.

2.7. Statistical Analysis. The intensity of the protein bands from Western blot was analyzed by Image-Pro Plus software and ID Image Analysis software (KODAK, USA), respectively. The data were presented as mean \pm SD and were analyzed by analysis of variance.

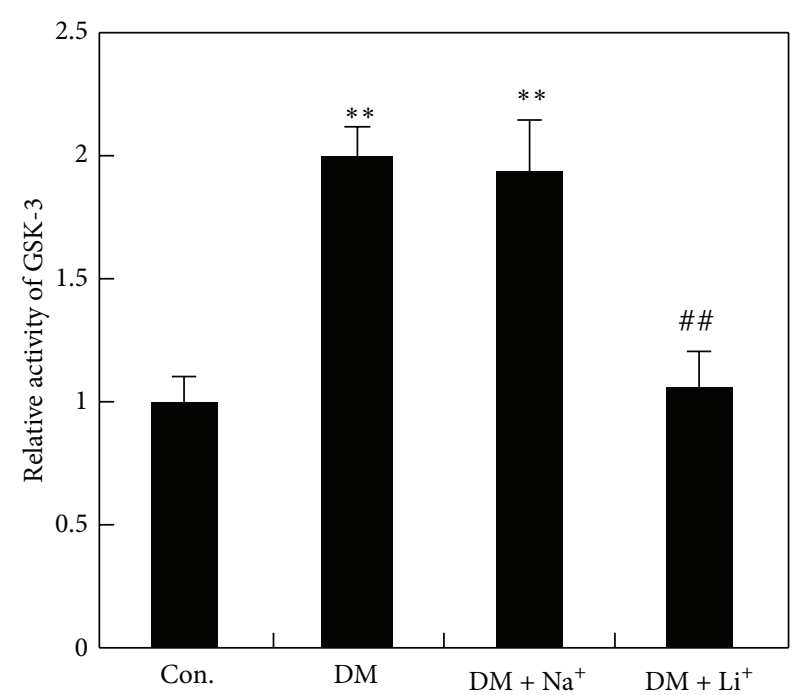

Figure 2: The activity of GSK-3. The activities of GSK-3 in hippocampal extracts from rats injected with STZ, STZ plus $\mathrm{NaCl}$, or STZ plus LiCl were determined by using specific peptide substrates. ${ }^{* *} P<0.01$ versus control group, ${ }^{\# \#} P<0.01$ versus DM group.

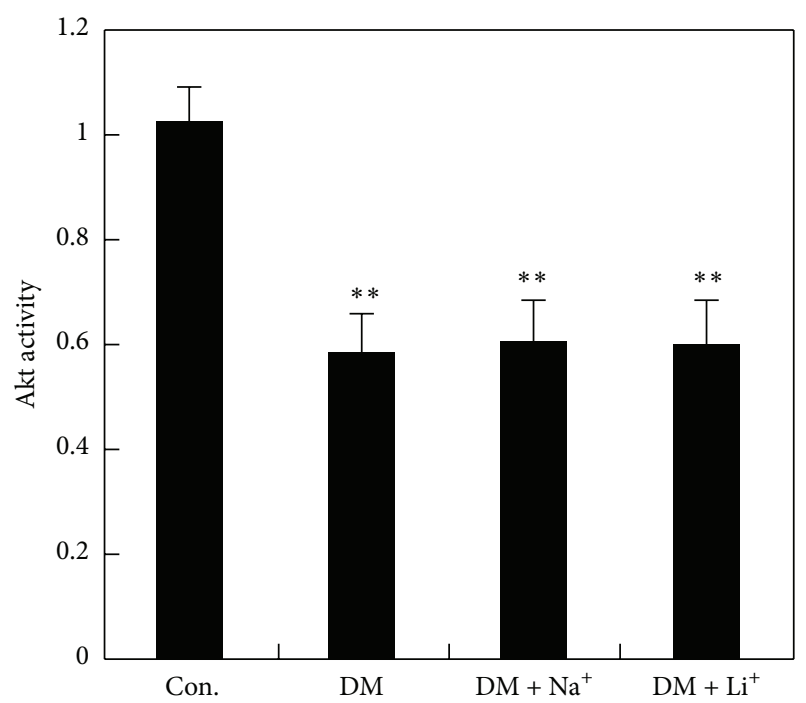

FIGURE 3: The activity of Akt. The activities of Akt in hippocampal extracts from rats injected with STZ, STZ plus $\mathrm{NaCl}$, or STZ plus $\mathrm{LiCl}$ were determined by using specific peptide substrates. ${ }^{* *} P<$ 0.01 versus control group.

\section{Results}

3.1. Measurement the Level of Serum Glucose in Rats. $72 \mathrm{~h}$ after STZ injection, the fasting blood glucose (FBG) of the rats among $\mathrm{DM}$ group, $\mathrm{DM}$ plus $\mathrm{NaCl}$ group, and $\mathrm{DM}$ plus $\mathrm{LiCl}$ group was over $16.7 \mathrm{mmol} / \mathrm{L}$, and it was increased obviously as compared with controls. The fasting blood glucose of the rats in $\mathrm{DM}$ plus $\mathrm{LiCl}$ group was not induced a significant decrease when compared with DM group, but there was a tendency toward decrease (Figure 1). 


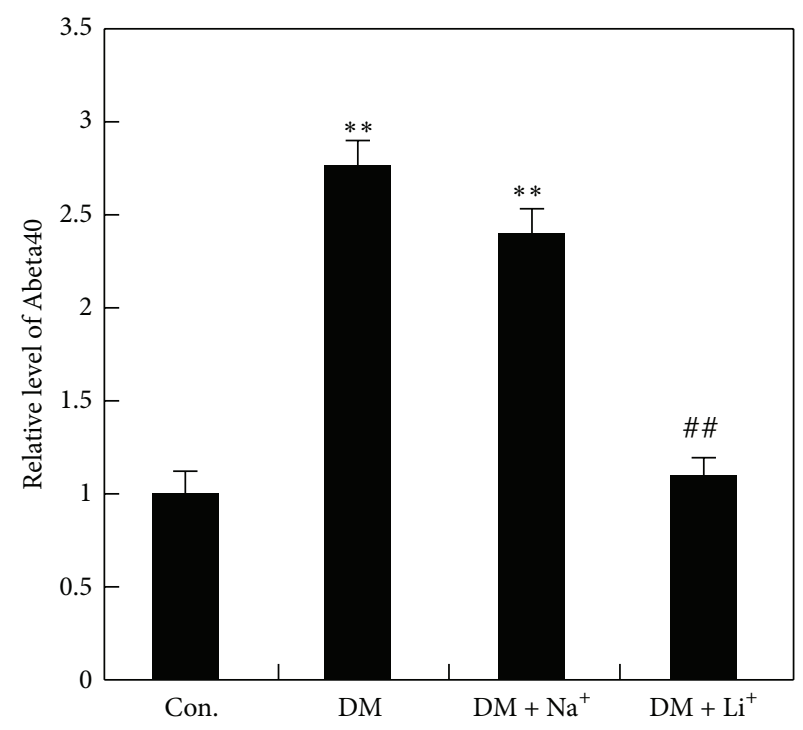

(a)

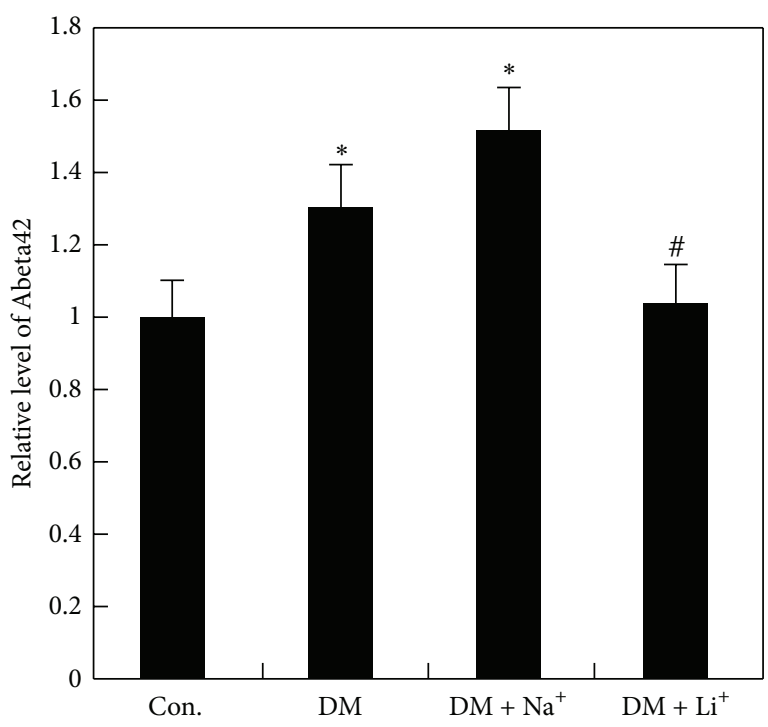

(b)

Figure 4: Production of $\mathrm{A} \beta 40$ (a) and $\mathrm{A} \beta 42$ (b) generation. STZ treatment increased $\mathrm{A} \beta 40$ and $\mathrm{A} \beta 42$ production significantly and LiCl could reverse the change induced by STZ treatment. ${ }^{*} P<0.05$ and ${ }^{* *} P<0.01$ versus control group, ${ }^{\#} P<0.05$ and ${ }^{\# \#} P<0.01$ versus DM group.
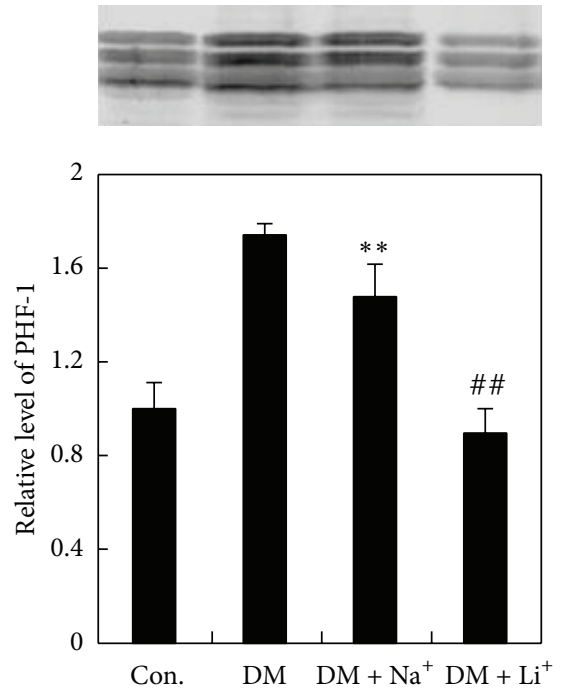

(a)
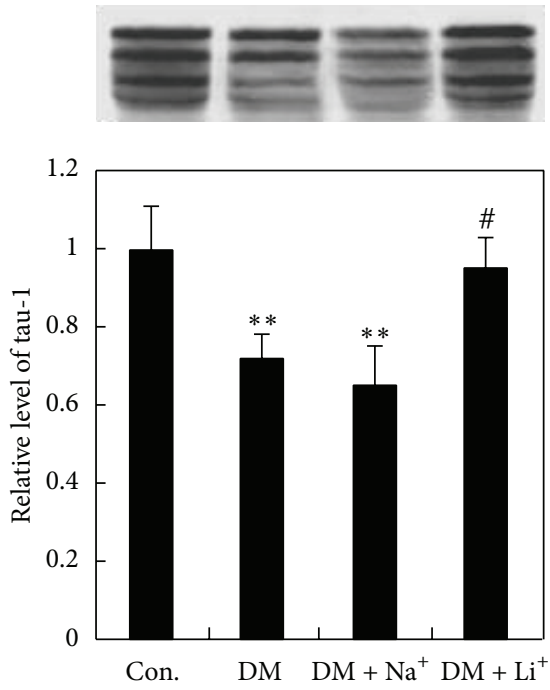

(b)
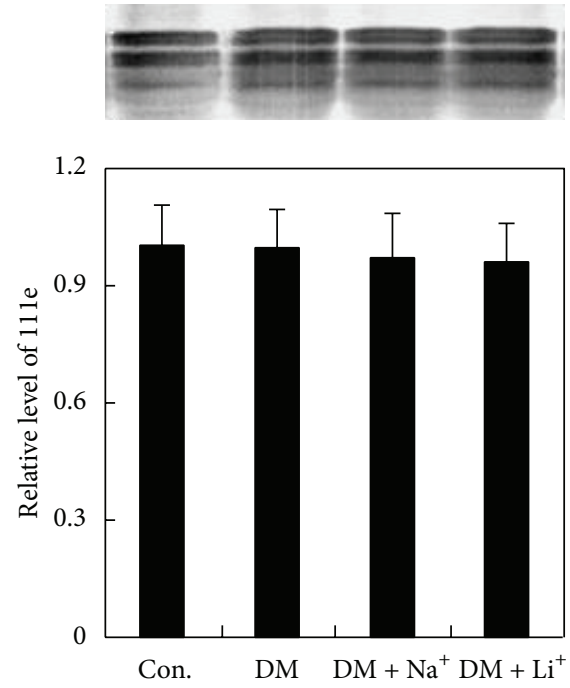

(c)

Figure 5: Tau phosphorylation. ${ }^{*} P<0.05$ and ${ }^{* *} P<0.01$ versus control group, ${ }^{\#} P<0.05$ and ${ }^{\# \#} P<0.01$ versus DM group.

3.2. Assay of the Activity of GSK-3 and Akt. To reveal the role of GSK-3 and Akt during the course of diabetes, activity of GSK-3 and Akt was measured (Figure 3). GSK-3 is an important kinase in the process of $\mathrm{A} \beta$ production and tau hyperphosphorylation $[3,4]$. GSK-3 was inactivated by phosphorylation of serine 9 in GSK- $3 \beta$ and serine 21 in GSK$3 \alpha$ [18]; Akt appears to be the predominant kinase mediating this phosphorylation of GSK-3. Both brain GSK-3 and Akt can be regulated by blood glucose in mice [18]. In our study, we found the strong activity of GSK-3 and lower activity in rat hippocampus when fasting blood glucose was highly increased by STZ intraperitoneal injection. After treating the DM rats with $\mathrm{LiCl}$, GSK-3 activity was decreased $46 \%$ approximately. No apparent inhibition of GSK-3 activity was observed after treating the $\mathrm{DM}$ rats with $\mathrm{NaCl}$ (Figure 2). There were not obvious changes of Akt activity after treatment of $\mathrm{LiCl}$ or $\mathrm{NaCl}$ with $\mathrm{DM}$ rats. These results implied that hyperglycemia induced strong activity of GSK-3 and lower activity of Akt in rat brain. $\mathrm{LiCl}$ could directly inhibit the activity of GSK-3 rather than Akt.

3.3. Assay Production of $A \beta$ and Tau Phosphorylation and the Role of $\mathrm{LiCl}$. A $\beta$ deposition is an important mechanism in 
both $\mathrm{AD}$ and diabetes, and GSK-3 plays an important role in regulation of $A \beta$ production. The high level of GSK- 3 activity and low level of Akt activity were found in our study. To elucidate the effects of GSK- 3 and Akt on $\mathrm{A} \beta$ production, $\mathrm{A} \beta$ production was determined following measurement of GSK-3 and Akt activity. As shown in Figure 4, the production of $\mathrm{A} \beta 40$ (Figure 4(a)) and $\mathrm{A} \beta 42$ (Figure 4(b)) was increased significantly while activation of GSK-3 and inhibition of Akt were induced in DM group. After treating the DM rats with $\mathrm{LiCl}$, the production of $\mathrm{A} \beta 40$ and $\mathrm{A} \beta 42$ was reduced by $60 \%$ and $21 \%$, respectively. There was not significant reduction of $\mathrm{A} \beta 40$ and $\mathrm{A} \beta 42$ following $\mathrm{NaCl}$ treatment. These data showed that production of $A \beta 40$ and $A \beta 42$ is increased in the hippocampus of DM rats; both activation of GSK-3 and inhibition of Akt might play an important role in this process.

GSK-3 is also an important kinase in the regulation of tau phosphorylation. When itwas activated, tau was prone to phosphorylation at ser198/ser199/ser202 sites and ser396/ser404 sites. Hence, we examined the state of tau phosphorylation in DM rat by Western blot using phosphorylation-dependent and site-specific tau antibodies. We found that in DM rat hippocampus, the immunoreactivity of PHF-1 (detection of ser396/ser404, phosphorylated sites) was increased obviously as compared with the control group, but the staining of PHF-1 was reversed after treatment of $\mathrm{LiCl}$ (Figure 5(a)). Moreover, the immunoreactivity of Tau-1 (detection of ser198/ser199/ser202, nonphosphorylated sites) was decreased in DM rat as compared with controls, and $\mathrm{LiCl}$ could reverse this staining (Figure 5(b)). $\mathrm{NaCl}$ treatment did not change the staining of PHF- 1 and Tau- 1 in the DM group. The total level of tau measured by R11le was not changed significantly in all the four groups (Figure 5(c)).

3.4. Assay of Akt Expression. GSK-3 was inactivated by Akt by phosphorylation at serine 9 and serine 21. To test if Akt was regulated by streptozotocin-induced hyperglycemia and was regulated by activation of GSK-3, we examined phosphorylation level of Akt. Our results show that the phosphorylation of Akt at Ser 473 site was deceased in DM rat hippocampus, and both $\mathrm{LiCl}$ and $\mathrm{NaCl}$ administration could not recover the decrease, and the total level of Akt was not changed. These results suggest that GSK-3 was inhibited by $\mathrm{LiCl}$ instead of Akt inhibition (Figure 6).

3.5. Behavioral Testing. To further explore the cognition dysfunction caused by the changes of Akt and GSK-3 and Tau hyperphosphorylation in DM rats, the step-down electronic inhibitory avoidance task was assessed in rats. To examine which rats have lower ability of learning and memory, we first trained all rats to stay on the platform for $3 \mathrm{~min}$ and not to step down. Ninety-four hours after the training, latencies to stepdown during training session were not significantly different across the groups (data are not shown because the latency to step-down in this session was basically nonexistent). The results suggest significantly shorter latencies and more error times to step-down in DM rat when compared to control groups $(P<0.05)$. Longer latencies and less error times were observed in $\mathrm{LiCl}$ administration to DM rat as compared with
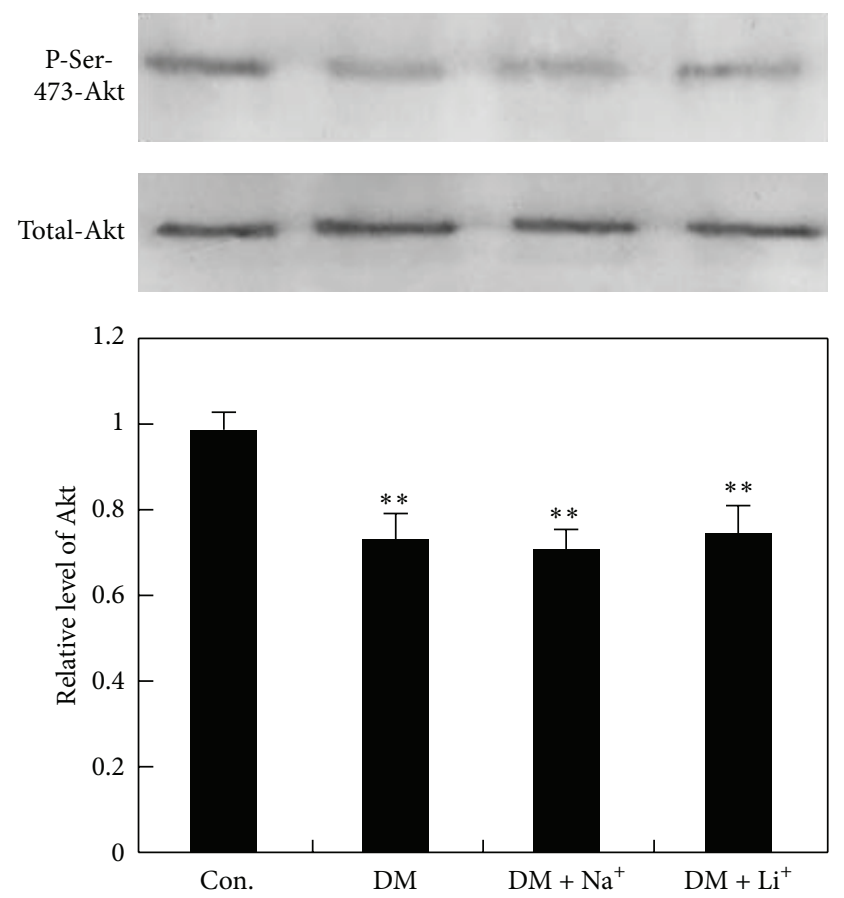

FIGURE 6: Akt expression. ${ }^{* *} P<0.01$ versus control group.

DM rat $(P<0.05)$. There is no significant difference between $\mathrm{NaCl}$ administration to DM rats and DM rats $(P>0.05)$. These results suggest that inhibition of $\mathrm{LiCl}$ on GSK-3 might improve the memory of DM rat (Figure 7).

\section{Discussion}

Study and memory dysfunction are the main phenomena of central nervous system complications in type I diabetes mellitus [21]. Cerebral atrophy, which is characterized in $\mathrm{AD}$ patients, is also found in young patients with type 1 diabetes who are otherwise healthy [22]. In experimental animal models, an increase of stains with $\mathrm{A} \beta 40$ and $\mathrm{A} \beta 42$ antibody is induced in DM mice hippocampus [9]. Tau is also hyperphosphorylated at ser199/ser202 while the expression of GSK-3 is decreased in DM mice hippocampus [13]. Whether $\mathrm{A} \beta$ overproduction and tau hyperphosphorylation happen synchronously in the hippocampus of DM rat is puzzling, and the role of GSK-3 and Akt in these processes is not clear.

Both GSK-3 and Akt in mice brain could be regulated by alterations of blood glucose; streptozotocin-induced hyperglycemia brain increases Akt activity and decreases GSK-3 activity, which could be reversed by lowering blood glucose with insulin administration [18]. In an experimental model related to sporadic Alzheimer's disease, after intracerebroventricular injection of streptozotocin for 1 month, there is a decrease of GSK-3 alpha/beta activity in the rat hippocampus [5]. In our study, the hyperglycemia was induced by intraperitoneal injection of rats with streptozotocin, but an increase of GSK-3 activity and a decrease of Akt activity were induced in the rat hippocampus. Hence, we proposed 


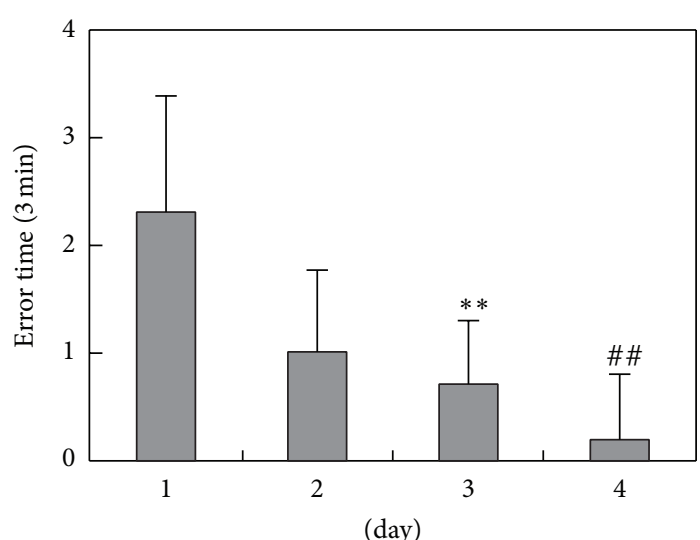

(a)

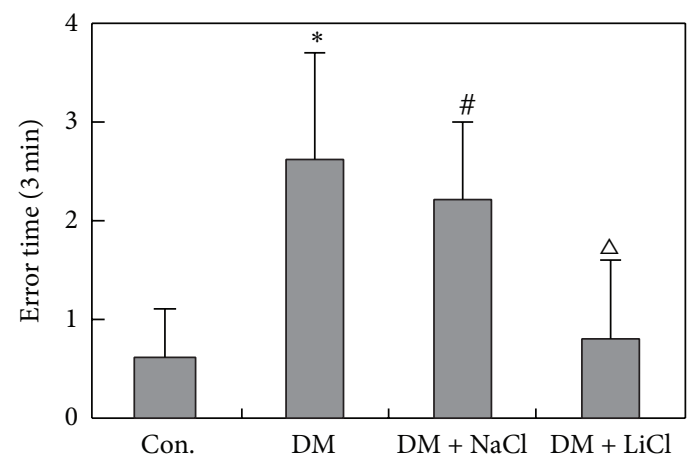

(c)

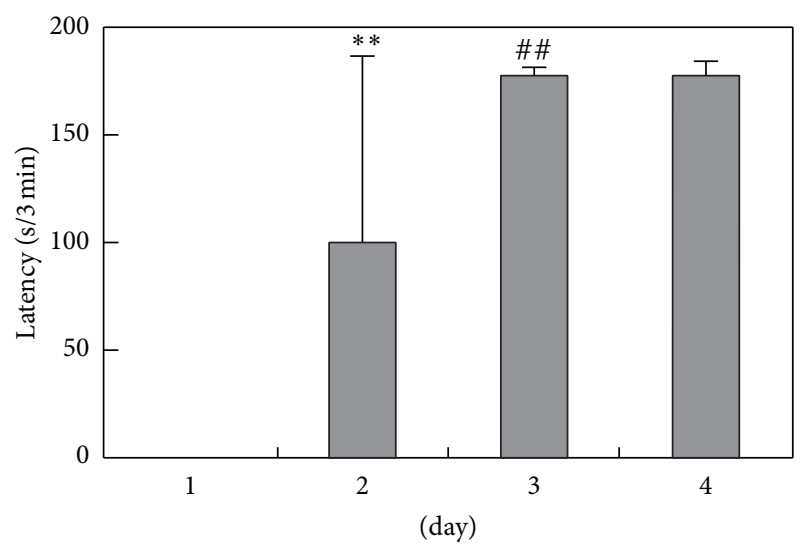

(b)

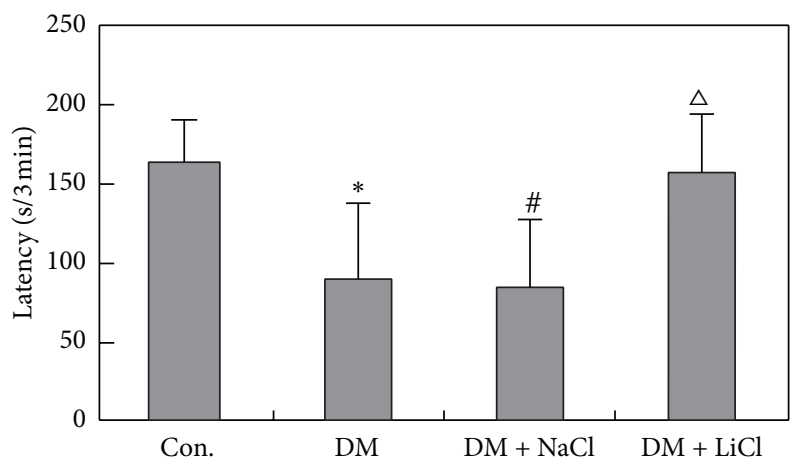

(d)

FIGURE 7: Step-down electronic inhibitory avoidance task. ${ }^{*} P<0.05,{ }^{\#} P<0.05$ versus Con. group, ${ }^{\triangle} P<0.05$ versus DM group. (a) The error time before modeling. The error time reached the similar time level after the rats were trained for $4 \mathrm{~d}$. ${ }^{* *} P<0.01,{ }^{\# \#} P<0.01$ versus $1 \mathrm{~d}$. (b) The latency before modeling. The latency was increased after the rats were trained for $3 \mathrm{~d}$ and $4 \mathrm{~d}$. ${ }^{* *} P<0.01,{ }^{\# \#} P<0.01$ versus $4 \mathrm{~d}$. (c) The error time at 10 days after $\mathrm{LiCl}$ administration. The error time increased in DM group but decreased in group with LiCl administration for 10 days. ${ }^{*} P<0.05,{ }^{\#} P<0.05$ versus Con. group, ${ }^{\triangle} P<0.05$ versus DM group. (d) The latency at 10 days after LiCl administration. The latency decreased in DM group but increased in group treated with $\mathrm{LiCl}$ administration for 10 days. ${ }^{*} P<0.05$, ${ }^{\#} P<0.05$ versus Con, ${ }^{\triangle} P<0.05$ versus DM.

that hyperglycemia might affect the activities of GSK-3 and Akt in DM rat brain. In AD-like Tg2576 mice, diet-induced insulin resistance promotes Abeta40 and Abeta42 peptide generation in the brain that corresponds with increased gamma-secretase activities. Further exploration of the apparent interrelationship of insulin resistance to brain amyloidosis reveals a functional decrease in insulin receptor- (IR-) mediated signal transduction in the brain; Akt/PKB inhibits glycogen synthase kinase (GSK-3 alpha) activity [3]. We also found that there was an increase of $A \beta$ production when GSK-3 activity was increased and PKB activity was decreased in the hippocampus of DM rats. Lithium, a specific inhibitor of GSK- $3 \alpha$ and GSK- $3 \beta$, reduces $A \beta$ production by interfering with APP cleavage at the $\gamma$-secretase step and is found to reduce $A \beta$ production in the mice expressing pathogenic familial Alzheimer's disease [3]. In our study, after treating DM rats with $\mathrm{LiCl}$, GSK-3 activity was decreased significantly in the hippocampus, and $\mathrm{A} \beta 40$ and $\mathrm{A} \beta 42$ were reduced by $60 \%$ and $21 \%$, but administration of DM rats with $\mathrm{NaCl}$ reduced neither the activation of GSK-3 nor the overproduction of $A \beta 40$ and $A \beta 42$. The low level activity of Akt maintained in $\mathrm{LiCl}$ administration showed that lithium could not inhibit Akt in DM rat brain. These data suggested that GSK-3 played an important role in $\mathrm{A} \beta$ overproduction of DM rat hippocampus.

On the other hand, $\mathrm{LiCl}$, as a specific GSK-3 inhibitor, has been confirmed to block tau hyperphosphorylation either in culture neuron or in rat brain $[23,24]$. The major kinase for tau phosphorylation is GSK3 $\beta$. Smaller contributions of GSK $3 \alpha$, cdk-5, and MAPK are suggested [25]. In DM mice hippocampus, tau is hyperphosphorylated at ser199/ ser202 sites with lower GSK-3 expression [13]. In our study, we found that tau hyperphosphorylation was induced at ser198/ser199/ser202, Ser396/Ser404 sites just when the activity of GSK-3 increased highly. When the DM rats were treated with $\mathrm{LiCl}$, GSK-3 activity decreased about $46 \%$, and hyperphosphorylation tau was reversed at ser396/ser404, ser198/ser199/ser202 sites in the hippocampus. These sites are just the targets of GSK-3 [26], while $\mathrm{NaCl}$ treatment showed no apparent changes in these sites as compared with DM rats. 
These data also suggested that $\mathrm{LiCl}$ reduced tau hyperphosphorylation at ser396/ser404, ser198/ser199/ser202 in DM rat hippocampus by inhibition of GSK-3 rather than of Akt (PKB).

Tau hyperphosphorylation may be associated with cognitive impairment [27, 28]. Whether the changes of Akt and GSK-3 may reduce memory retention in DM rat is not sure. Our results suggest that the increase of GSK-3 may be response for the impairment of step-down inhibitory avoidance task rather than Akt because the activities and the expression of Akt were not significantly different among DM group, $\mathrm{DM}+\mathrm{NaCl}$ group, and $\mathrm{DM}+\mathrm{LiCl}$ group, but other studies show that learning impairment and hippocampal ERK and Akt inactivation are induced by scopolamine in male Sprague-Dawley rats [29].

In conclusion, our results demonstrate that GSK-3 has an important role in the pathogenesis of diabetic neurological complications byregulation of $\mathrm{A} \beta$ production and tau hyperphosphorylation, and the present data suggest that GSK-3 might be a key target in the therapy of central nervous system neuropathy of diabetes mellitus.

\section{Conflict of Interests}

The authors declare that there is no conflict of interests regarding the publication of this paper.

\section{Authors' Contribution}

Zhong-Sen Qu and Liang Li contributed to this work equally.

\section{Acknowledgment}

This work was supported by the Grants from China Postdoctoral Science Foundation (20060390635).

\section{References}

[1] D. J. Selkoe, “The cell biology $\beta$-amyloid precursor protein and presenilin in Alzheimer's disease," Trends in Cell Biology, vol. 8, no. 11, pp. 447-453, 1998.

[2] I. Grundke-Iqbal, K. Iqbal, and Y.-C. Tung, "Abnormal phosphorylation of the microtubule-associated protein $\tau$ (tau) in Alzheimer cytoskeletal pathology," Proceedings of the National Academy of Sciences of the United States of America, vol. 83, no. 13, pp. 44913-4917, 1986.

[3] C. J. Phiel, C. A. Wilson, V. M.-Y. Lee, and P. S. Klein, "GSK-3 $\alpha$ regulates production of Alzheimer's disease amyloid$\beta$ peptides," Nature, vol. 423, no. 6938, pp. 435-438, 2003.

[4] J. L. Shi, Y. Z. Jia, L. L. Hong et al., "Tau becomes a more favorable substrate for GSK-3 when it is prephosphorylated by PKA in rat brain," The Journal of Biological Chemistry, vol. 279, no. 48, pp. 50078-50088, 2004.

[5] M. Salkovic-Petrisic, F. Tribl, M. Schmidt, S. Hoyer, and P. Riederer, "Alzheimer-like changes in protein kinase B and glycogen synthase kinase- 3 in rat frontal cortex and hippocampus after damage to the insulin signalling pathway," Journal of Neurochemistry, vol. 96, no. 4, pp. 1005-1015, 2006.
[6] W. L. Xu, C. X. Qiu, Å. Wahlin, B. Winblad, and L. Fratiglioni, "Diabetes mellitus and risk of dementia in the Kungsholmen project: a 6-year follow-up study," Neurology, vol. 63, no. 7, pp. 1181-1186, 2004.

[7] A. Ott, R. P. Stolk, F. van Harskamp, H. A. Pols, A. Hofman, and M. M. Breteler, "Diabetes mellitus and the risk of dementia: the Rotterdam study," Neurology, vol. 53, no. 9, pp. 1937-1942, 1999.

[8] M. R. Nicolls, "The clinical and biological relationship between Type II diabetes mellitus and Alzheimer's disease," Current Alzheimer Research, vol. 1, no. 1, pp. 47-54, 2004.

[9] S. Shuli, Z. Yongmei, Z. Zhijuan, and J. Zhiwei, “ $\beta$-Amyloid and its binding protein in the hippocampus of diabetic mice: effect of APP17 peptide," NeuroReport, vol. 12, no. 15, pp. 3317-3319, 2001.

[10] L. Ho, W. Qin, P. N. Pompl et al., "Diet-induced insulin resistance promotes amyloidosis in a transgenic mouse model of Alzheimer's disease," The FASEB Journal, vol. 18, no. 7, pp. 902-904, 2004.

[11] O. Kaidanovich and H. Eldar-Finkelman, "The role of glycogen synthase kinase- 3 in insulin resistance and Type 2 diabetes," Expert Opinion on Therapeutic Targets, vol. 6, no. 5, pp. 555-561, 2002.

[12] H. Eldar-Finkelman, S. A. Schreyer, M. M. Shinohara, R. C. LeBoeuf, and E. G. Krebs, "Increased glycogen synthase kinase3 activity in diabetes- and obesity- prone C57BL/6J mice," Diabetes, vol. 48, no. 8, pp. 1662-1666, 1999.

[13] Y.-M. Zhao, J.-J. Pei, Z.-J. Ji, Z.-W. Zhao, Y.-Y. Qian, and S.-L. Sheng, "Effect of amyloid precursor protein 17 mer peptide on microtubule structure and tau protein hyperphosphorylation in hippocampal neurons of experimental diabetic mice," NeuroReport, vol. 14, no. 1, pp. 61-66, 2003.

[14] R. Schechter, D. Beju, and K. E. Miller, "The effect of insulin deficiency on tau and neurofilament in the insulin knockout mouse," Biochemical and Biophysical Research Communications, vol. 334, no. 4, pp. 979-986, 2005.

[15] V. Stambolic, L. Ruel, and J. R. Woodgett, "Lithium inhibits glycogen synthase kinase-3 activity and mimics wingless signalling in intact cells," Current Biology, vol. 6, no. 12, pp. 1664$1668,1996$.

[16] T. Tanaka, J. Zhong, K. Iqbal, E. Trenkner, and I. Grundke-Iqbal, "The regulation of phosphorylation of $\tau$ in SY5Y neuroblastoma cells: the role of protein phosphatases," The FEBS Letters, vol. 426, no. 2, pp. 248-254, 1998.

[17] A. Jacob, D. Cooney, S. Tridandapani, T. Kelley, and K. M. Coggeshall, " $F c \gamma$ RIIb modulation of surface immunoglobulininduced Akt activation in murine B cells," The Journal of Biological Chemistry, vol. 274, no. 19, pp. 13704-13710, 1999.

[18] B. Clodfelder-Miller, P. de Sarno, A. A. Zmijewska, L. Song, and R. S. Jope, "Physiological and pathological changes in glucose regulate brain Akt and glycogen synthase kinase-3," The Journal of Biological Chemistry, vol. 280, no. 48, pp. 39723-39731, 2005.

[19] Y.-C. Zhang, Z.-F. Wang, Q. Wang, Y.-P. Wang, and J.-Z. Wang, "Melatonin attenuates $\beta$-amyloid-induced inhibition of neurofilament expression," Acta Pharmacologica Sinica, vol. 25, no. 4, pp. 447-451, 2004.

[20] M. Bennecib, C.-X. Gong, I. Grundke-Iqbal, and K. Iqbal, "Role of protein phosphatase-2A and -1 in the regulation of GSK-3, cdk 5 and cdc 2 and the phosphorylation of tau in rat forebrain," The FEBS Letters, vol. 485, no. 1, pp. 87-93, 2000.

[21] A. D. Mooradian, "Pathophysiology of central nervous system complications in diabetes mellitus," Clinical Neuroscience, vol. 4, no. 6, pp. 322-326, 1997. 
[22] G. J. Biessels, L. P. van der Heide, A. Kamal, R. L. A. W. Bleys, and W. H. Gispen, "Ageing and diabetes: implications for brain function," European Journal of Pharmacology, vol. 441, no. 1-2, pp. 1-14, 2002.

[23] J. R. Muñoz-Montaño, F. J. Moreno, J. Avila, and J. DíazNido, "Lithium inhibits Alzheimer's disease-like tau protein phosphorylation in neurons," FEBS Letters, vol. 411, no. 2-3, pp. 183-188, 1997.

[24] M. Hong, D. C. R. Chen, P. S. Klein, and V. M.-Y. Lee, "Lithium reduces tau phosphorylation by inhibition of glycogen synthase kinase-3," The Journal of Biological Chemistry, vol. 272, no. 40, pp. 25326-25332, 1997.

[25] Y. Tomidokoro, K. Ishiguro, Y. Harigaya et al., "A $\beta$ amyloidosis induces the initial stage of tau accumulation in APPSw mice," Neuroscience Letters, vol. 299, no. 3, pp. 169-172, 2001.

[26] T. Li and H. K. Paudel, "Glycogen synthase kinase $3 \beta$ phosphorylates Alzheimer's disease-specific Ser396 of microtubuleassociated protein tau by a sequential mechanism," Biochemistry, vol. 45, no. 10, pp. 3125-3133, 2006.

[27] Y.-G. Chen, "Specific tau phosphorylation sites in hippocampus correlate with impairment of step-down inhibitory avoidance task in rats," Behavioural Brain Research, vol. 158, no. 2, pp. 277284, 2005.

[28] H. Le Freche, J. Brouillette, F.-J. Fernandez-Gomez et al., “Tau phosphorylation and sevoflurane anesthesia: an association to postoperative cognitive impairment," Anesthesiology, vol. 116, no. 4, pp. 779-787, 2012.

[29] M. Moosavi, G. Yadollahi Khales, L. Abbasi, A. Zarifkar, and K. Rastegar, "Agmatine protects against scopolamine-induced water maze performance impairment and hippocampal ERK and Akt inactivation," Neuropharmacology, vol. 62, no. 5-6, pp. 2018-2023, 2012. 

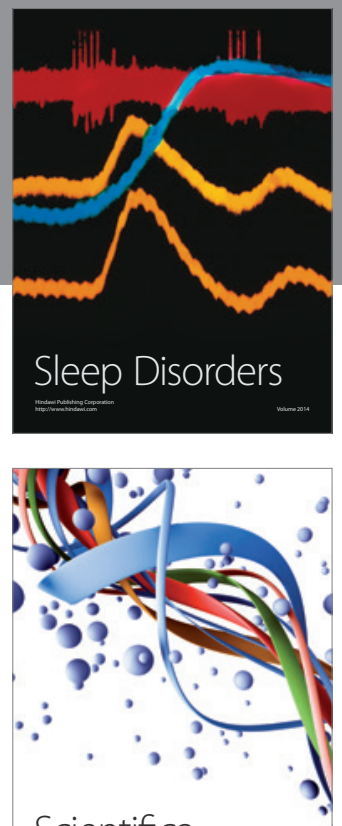

Scientifica
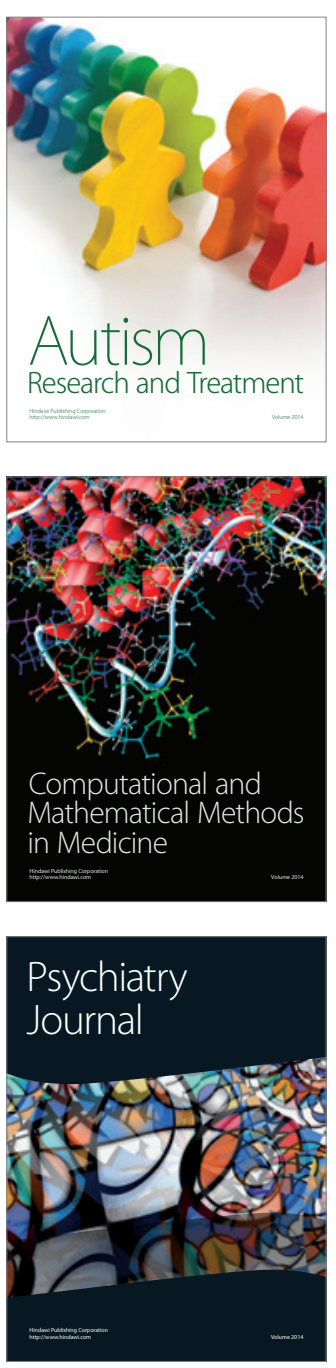
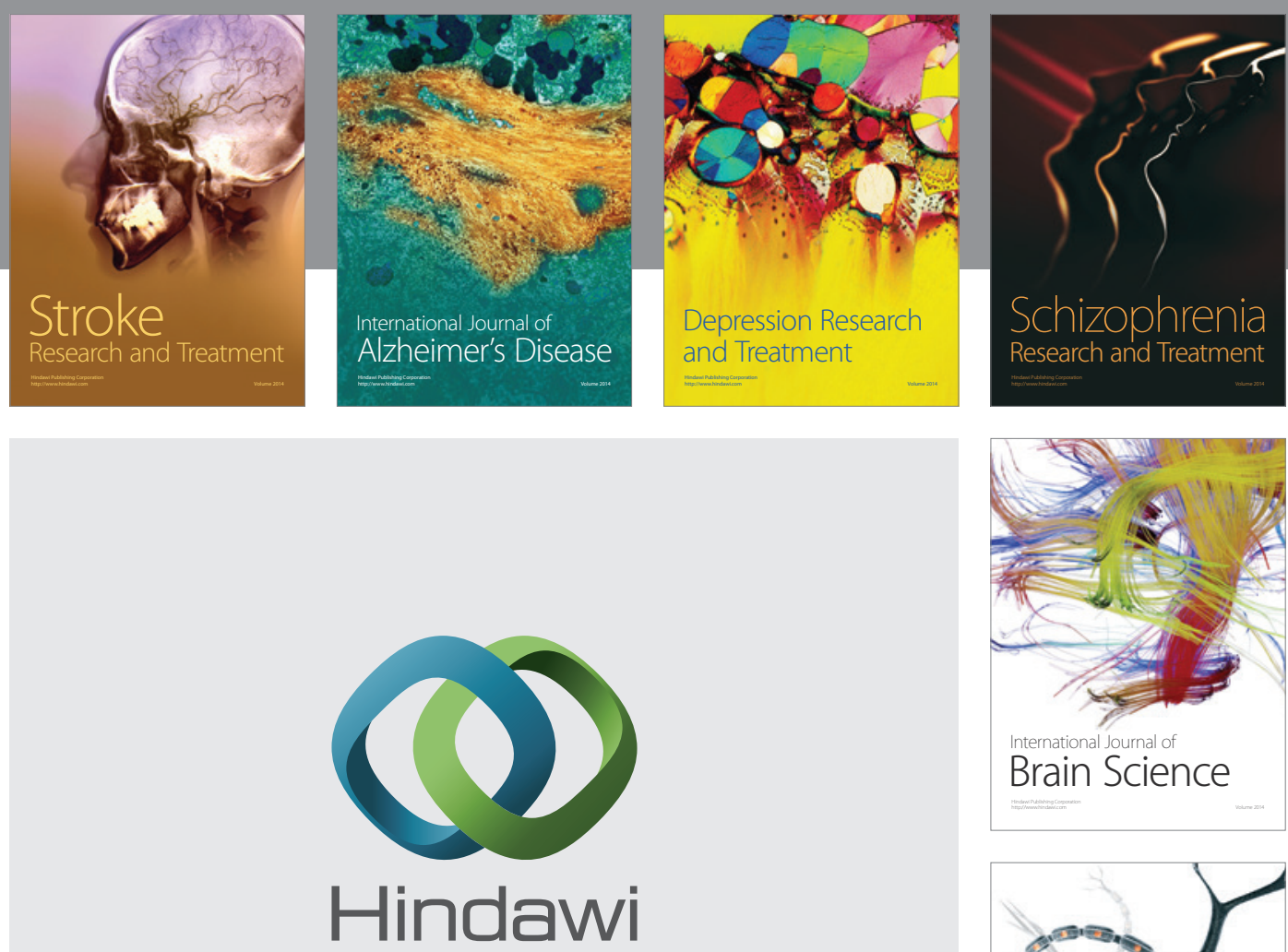

Submit your manuscripts at

http://www.hindawi.com
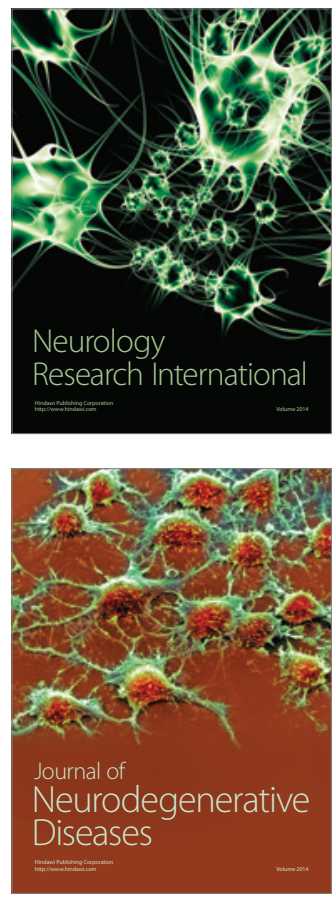

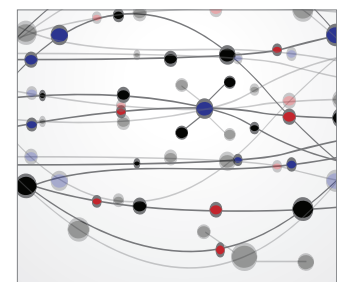

The Scientific World Journal
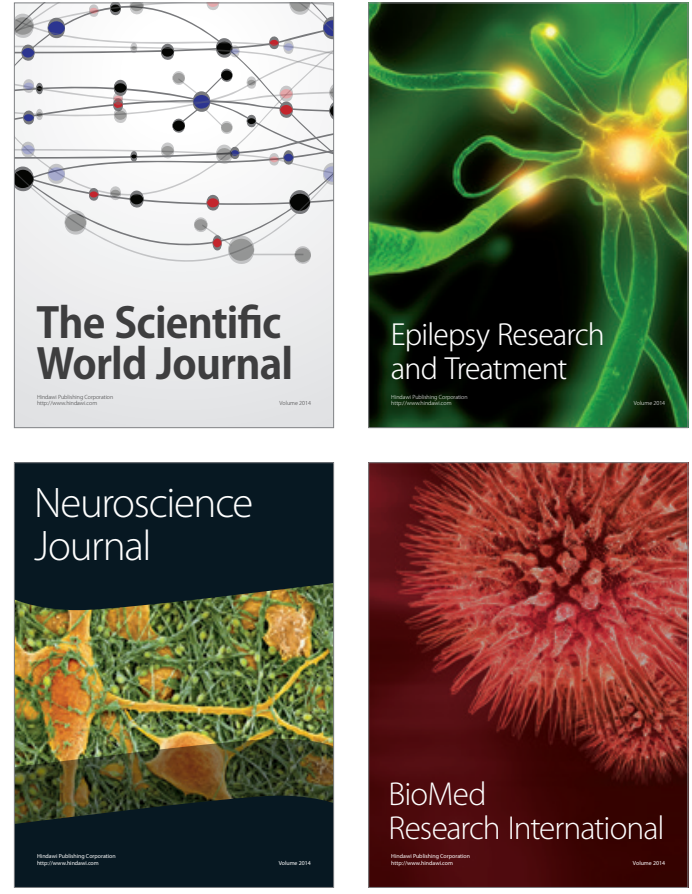

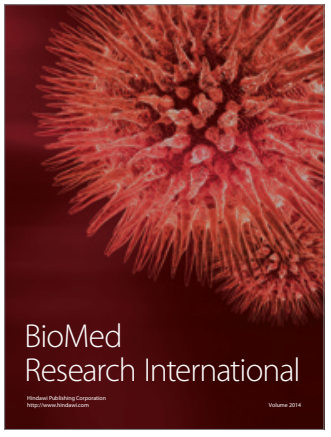

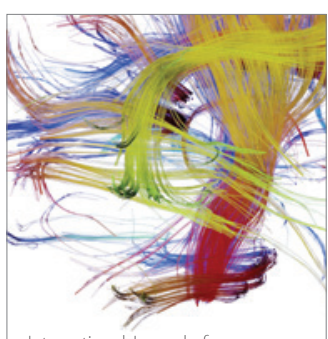

Brain Science

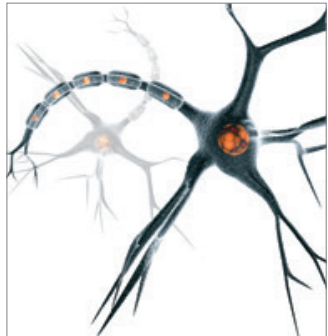

Neural Plasticity
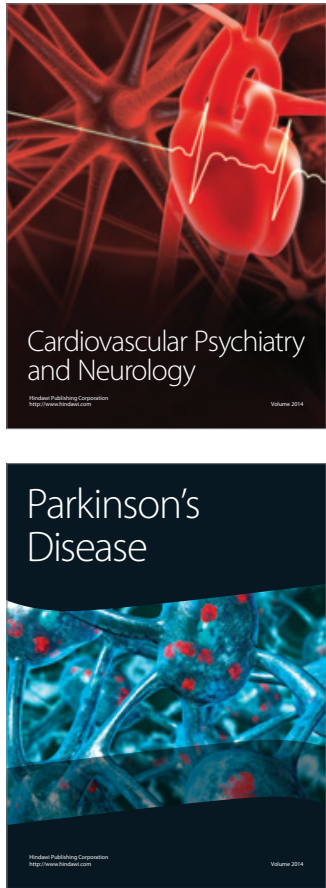